Article type : Original Article

\title{
Cauliflower ear among Finnish high-level male wrestlers and judokas is prevalent and symptomatic deformity
}

Running head: Cauliflower ear among wrestlers and judokas

Authors:

Iida-Kaisa Manninen ${ }^{1}$

Karin Blomgren ${ }^{1}$

Rauno Elokiuru ${ }^{2}$

Mika Lehto ${ }^{3}$

Laura K Mäkinen ${ }^{1}$

Tuomas Klockars ${ }^{1}$

${ }^{1}$ Department of Otorhinolaryngology, Head and Neck Surgery, Helsinki University Hospital and University of Helsinki, Helsinki, Finland

2 KIHU - Research Institute for Olympic Sports, Jyväskylä, Finland

${ }^{3}$ Heart and Lung Center, Helsinki University Hospital, Helsinki, Finland

Corresponding author

Address: Iida-Kaisa Manninen, Kasarmikatu 11-13, Helsinki, PL 263, 00029 HUS

iida-kaisa.manninen@helsinki.fi

+358504620696

\section{ABSTRACT}

Our research aimed to study the prevalence, concerns and treatment practices related to cauliflower ear among Finnish wrestlers and judokas. In total 32 Finnish wrestlers and 31 judokas completed a questionnaire at training sessions or at a competition. All participants were adults competing at the national or international levels. We also took lateral digital photographs of participants' ears. A senior author graded the overall appearance of the auricles on a scale from 0 to 5 ( $0=$ normal auricle, 5 = extreme cauliflower ear). Cauliflower ear was more prevalent among male athletes $(84 \%, 46 / 55)$ than female athletes $(0 \%, 0 / 8, p<0.001)$. Almost all $(96 \%)$ had sought treatment for an auricular haematoma. The most prevalent treatment modality was needle aspiration (96\%). Most $(76 \%)$ had received treatment

This article has been accepted for publication and undergone full peer review but has not been through the copyediting, typesetting, pagination and proofreading process, which may lead to differences between this version and the Version of Record. Please cite this article as doi: $10.1111 / \mathrm{sms} .13530$

This article is protected by copyright. All rights reserved. 
from individuals not representing the healthcare profession. Only one athlete reported receiving successful treatment. No complications from treatment were reported. Almost all participants (96\%) reported some symptom from the cauliflower ear, typically pain. None regretted their cauliflower ear(s) and $41 \%$ of athletes with cauliflower ear considered it desirable. Cauliflower ear is a common and symptomatic deformity among high-level Finnish wrestlers and judokas. Despite the symptoms, it is accepted and sometimes even desired among the athletes.

Keywords: Judo, wrestling, wrestler's ear, ear deformity, sport injury.

\section{INTRODUCTION}

Cauliflower ear, or wrestler's ear, is an acquired deformity of the auricle caused by blunt trauma, occurring most frequently among martial arts athletes,,$^{1-4}$ with a prevalence among wrestlers of $39 \%$ to $44 \% .{ }^{1,2}$ Injury to the auricle causes a haematoma between the perichondrium and the auricular cartilage, thus decreasing perichondrial blood flow resulting in cartilage necrosis followed by fibroneocartilage formation. ${ }^{5}$ Cauliflower ear may cause aesthetic discomfort. ${ }^{3}$ In addition, possible ear canal obstruction may cause cerumen accumulation, external ear infections and even hearing loss. ${ }^{2,3,6}$

Auricular haematomas should be evacuated promptly to avoid the formation of cauliflower ear and a poor cosmetic outcome.7 Treatment options include aspiration or incision with post-drainage interventions such as suturing, dressings or splints to prevent the re-accumulation of the haematoma. ${ }^{8}$ In addition, protective headgear is suggested to reduce the occurrence of cauliflower ear. ${ }^{1}$

Our research aimed to study the prevalence, concerns and treatment practices related to cauliflower ear among Finnish wrestlers and judokas. 


\section{MATERIALS AND METHODS}

We distributed a four-page hardcopy questionnaire (see supplementary file) including a written informed consent form to Finnish wrestlers or judokas attending training camps, regular training sessions or a competition. All participants were adults competing at the national or international levels.

The questionnaire consisted of questions about possible cauliflower ear, training history and the use of headgear. If an athlete reported a cauliflower ear, s/he was further asked about the laterality, the age at which it occurred and possible treatments. Participants were also asked to grade possible symptoms (pain, warmth, ulcers, infections, earwax problems, hearing problems, cold sensitivity, dysaesthesia and sunburn) on a five-point Likert scale $(1=$ no harm, $5=$ a lot of harm $) .{ }^{9}$ In addition, this questionnaire was designed to reveal participants' attitudes on cauliflower ear, and included both fixed-choice and open-ended questions.

We also took lateral digital photographs of participants' ears. These pictures were later analysed and graded by the senior author (TK) who was unaware of the participant's sport and responses. The auricles were subjectively graded on a scale from 0 to $5(0=$ normal auricle, $5=$ extreme cauliflower ear, Figure 1$)$, based on the conchal region effect, lateral prominence and overall appearance.

An independent consultant from Elisa Appelsiini Oy (Helsinki, Finland) completed all statistical analyses. The ethics committee of the Helsinki University Hospital (HUS/2441/2017) approved the study protocol. Written informed consent was obtained from all participants. 


\section{RESULTS}

\section{Demography}

In total, 63 athletes participated in this study, of whom 32 were wrestlers and 31 were judokas. We distributed 65 questionnaires of which 97\% (63/65) were returned. The majority of participants were men $(87 \%, 55 / 63)$, the mean age was 22 years and participants had trained an average of 15 years in their sport. Among participants, $73 \%(46 / 63)$ reported having a cauliflower ear, $61 \%$ of which were bilateral $(28 / 46)$ (Table 1).

Wrestlers and judokas did not differ with regards to age or years of training. None of the female athletes had a cauliflower ear $(0 \%, 0 / 8)$, while prevalence among men was higher $(84 \%, 46 / 55, p<0.001)$. However, the prevalence of cauliflower ear among male wrestlers $(90 \%, 28 / 31)$ and judokas $(75 \%, 18 / 24)$ did not differ statistically. One-fourth of the athletes reported at least occasional use of protective headgear, which was more common among judokas $(p=0.029)$. None of the participants used headgear on a regular basis, and the use of protective headgear was not gender-dependent (Table 2).

\section{Photographs}

We took lateral photographs of $73 \%(46 / 63)$ of participants, $89 \%(41 / 46)$ of which featured both ears (in total, 87 ear pictures). In 92\% (80/87) of the photographs, the participant and the senior author agreed on the diagnosis of cauliflower ear. The senior author assigned a mean grade of 3.0 for the participants' worse or only cauliflower ear, indicating various degrees of cauliflower ear exist. There were no 
significant differences between wrestlers and judokas. We did, however, find a correlation between a worse ear grade and ulcers $(r=0.48, p<0.01)$. No other symptom associated with the ear grade.

\section{Treatment}

Among the 47 athletes who reported an auricular haematoma, 45 (96\%) had sought for treatment (Table 2). Despite treatment, the haematoma resulted in the formation of cauliflower ear in all but one case $(98 \%, 44 / 45)$. The most prevalent treatment modality consisted of needle aspiration (96\%, 43/45), whereby the majority reported some improvement $(88 \%, 38 / 43)$. In addition, the majority of these athletes had received a pressure dressing following aspiration $(88 \%, 38 / 43)$. Other treatment options included ice or cold compression (36\%, 16/45) and surgery (7\%, 3/45). The number of treatments per athlete ranged from 1 to over 20 , with a mean of 8 treatments. No complications from treatment were reported.

Among athletes who sought help, treatment was most often provided by a medical doctor (58\%, 26/45). Others providing treatment included 'a friend' (42\%, 19/45), themselves $(33 \%, 15 / 45)$, a relative $(13 \%, 6 / 45)$, a nurse $(11 \%, 5 / 45)$ and a coach $(11 \%, 5 / 45)$.

\section{Symptoms}

Almost all participants $(96 \%, 44 / 46)$ reported some symptom from the cauliflower ear, typically pain. The majority of athletes with cauliflower ear $(61 \%, 28 / 46)$ graded their pain at 3 or more on a scale from 1 to 5 . Warmth was the second most common symptom, graded at 3 or more by $28 \%(13 / 46)$ of athletes with cauliflower ear. Less 
common symptoms included dysaesthesia, ulcers, cold sensitivity, earwax problems, hearing loss and infection (Table 3). We found no difference regarding symptoms between wrestlers and judokas.

\section{DISCUSSION}

\section{Prevalence}

Cauliflower ear is a commonly acquired deformity among national- and internationallevel Finnish wrestlers and judokas. Almost three-quarters (73\%) of our respondents reported at least one cauliflower ear, a finding clearly higher than previous reports in which prevalence reached approximately $40 \% .{ }^{1,2}$ Given our study design, a positive bias towards cauliflower ear is possible. Our athletes had markedly longer careers (15 years of training) in martial arts compared to previous studies..$^{1,2}$ Therefore, it seems highly probable that in wrestling and judo a male athlete will experience an auricular haematoma during their training career.

Cauliflower ear is significantly more prevalent among male athletes given that none of the female athletes in this study reported a cauliflower ear. However, the number of female athletes was small. There are several possible explanations for this gender difference. The most likely explanation is the trauma mechanism. Male athletes are stronger than females, thus causing greater injury during training or competition. Another explanation may result from cauliflower ear representing a desired deformity among a remarkable proportion of male athletes (see Table 2). Cauliflower ear might also be generally more acceptable among male athletes since it is considered a natural consequence of their sport. 


\section{Treatment}

Almost all athletes with cauliflower ear had sought treatment for their injury $(96 \%$, 44/46). Rather discouragingly, in this study the treatment did not seem to prevent the formation of cauliflower ear since only one athlete reported undergoing successful treatment. However, we did not ask, if treatment was done every single time after auricular injury. It is possible that proper treatment at every occasion could have prevented the formation of cauliflower ear. Nevertheless, we recommend treatment since the majority $(88 \%, 38 / 43)$ of athletes benefited from aspiration. Auricular haematoma was often treated by individuals not representing healthcare professionals $(76 \%, 34 / 45)$. Fortunately, despite this, complications remained scarce. Medical professionals should, however, be aware that instructions for draining a haematoma are abundantly available via YouTube and other Internet resources.

\section{Symptoms and attitudes towards cauliflower ear}

Limited research exists on the symptoms and concerns related to cauliflower ear. ${ }^{2,6}$ The deformity is almost always symptomatic, whereby $96 \%$ (44/46) of our athletes with cauliflower ear reported some related discomfort, among which pain was most prevalent. Reflecting current attitudes, 54\% (25/46) of athletes with cauliflower ear reported that it was disadvantageous when using earphones. Almost all $(93 \%, 43 / 46)$ athletes with cauliflower ear had received comments concerning their ears, although none viewed these as disturbing. Despite their symptoms and comments, none of the athletes regretted their cauliflower ear(s) or viewed it as an aesthetic disadvantage. Thus, cauliflower ear is unexpectedly often (among about $40 \%$ of 
athletes) considered a desired deformity, likely due to the 'street credibility' associated with it among martial arts athletes.

\section{Conclusions}

Cauliflower ear is a common and symptomatic deformity among elite Finnish wrestlers and judokas, although nearly all individuals affected by it sought treatment for their injury.

\section{PERSPECTIVE}

Limited research exists of the prevalence of cauliflower ear, ${ }^{1,2}$ and the symptoms and concerns related to it.2,6 Almost three-quarters (73\%) of our respondents reported at least one cauliflower ear, a finding clearly higher than previous reports in which prevalence reached approximately $40 \% .1,2$ Almost all (96\%) of the participating athletes had sought treatment for their auricular hematoma. The hematomas are often treated by individuals not representing healthcare professionals and instructions for draining a haematoma are abundantly available via Internet. Although the treatment does not seem to prevent the formation of cauliflower ear, the majority $(88 \%, 38 / 43)$ of athletes reported benefit from aspiration.

In our study the cauliflower deformity is almost always symptomatic, whereby $96 \%$ of our athletes with cauliflower ear reported some related discomfort, among which pain was most prevalent. Despite their symptoms, none of our athletes regretted their cauliflower ear(s) or viewed it as an aesthetic disadvantage. 


\section{REFERENCES}

1. Schuller DE, Dankle SK, Martin M, Strauss RH. Auricular injury and the use of headgear in wrestlers. Arch Otolaryngol Head Neck Surg. 1989;115:714-717.

2. Kordi R, Mansournia MA, Nourian RA, Wallace WA. Cauliflower ear and skin infections among wrestlers in Tehran. J Sports Sci Med. 2007;6:39-44.

3. Vogelin E, Grobbelaar AO, Chana JS, Gault DT. Surgical correction of the cauliflower ear. Br J Plast Surg. 1998;51:359-362. doi:

//doi.org/10.1054/bjps.1997.0033.

4. Yotsuyanagi T, Yamashita K, Urushidate S, Yokoi K, Sawada Y, Miyazaki S. Surgical correction of cauliflower ear. Br J Plast Surg. 2002;55:380-386. doi: //doi.org/10.1054/bjps.2002.3854.

5. Ohlsen L, Skoog T, Sohn SA. The pathogenesis of cauliflower ear. an experimental study in rabbits. Scand J Plast Reconstr Surg. 1975;9:34-39.

6. Noormohammadpour P, Rostami M, Nourian R, et al. Association between hearing loss and cauliflower ear in wrestlers, a case control study employing hearing tests. Asian J Sports Med. 2015;6:e25786. doi: 10.5812/asjsm.6(2)2015.25786.

7. Lee D, Sperling N. Initial management of auricular trauma. Am Fam Physician. 1996;53:2339-2344.

8. Jones SE, Mahendran S. Interventions for acute auricular haematoma. Cochrane Database Syst Rev. 2004;(2):CD004166. doi: 10.1002/14651858.CD004166.pub2 
9. Likert R. A technique for the measurement of attitudes. Arch Psychol. 1932;22 140:55.

Table 1. Demographic characteristics of participants

\begin{tabular}{|c|c|c|c|c|c|c|}
\hline & \multicolumn{2}{|c|}{$\begin{array}{c}\text { All } \\
(n=63)\end{array}$} & \multicolumn{2}{|c|}{$\begin{array}{c}\text { Wrestlers } \\
(n=32)\end{array}$} & \multicolumn{2}{|c|}{$\begin{array}{l}\text { Judokas } \\
(n=31)\end{array}$} \\
\hline Mean age & \multicolumn{2}{|c|}{$22.2(S D \pm 4.7)$} & \multicolumn{2}{|c|}{$22.7(S D \pm 5.0)$} & \multicolumn{2}{|c|}{$21.6(S D \pm 4.3)$} \\
\hline Years of training & \multicolumn{2}{|c|}{$14.6(S D \pm 3.8)$} & \multicolumn{2}{|c|}{$15.1(S D \pm 3.5)$} & \multicolumn{2}{|c|}{$14.0(S D \pm 4.0)$} \\
\hline Women & $13 \%$ & $8 / 63$ & $3 \%$ & $1 / 32$ & $23 \%$ & $7 / 31$ \\
\hline Cauliflower ear & $73 \%$ & $46 / 63$ & $88 \%$ & $28 / 32$ & $58 \%$ & $18 / 31$ \\
\hline Unilateral cauliflower ear & $29 \%$ & $18 / 63$ & $38 \%$ & $12 / 32$ & $19 \%$ & $6 / 31$ \\
\hline Bilateral cauliflower ear & $44 \%$ & $28 / 63$ & $50 \%$ & $16 / 32$ & $39 \%$ & $12 / 31$ \\
\hline
\end{tabular}

Table 2. Use of headgear, treatment of auricular haematoma and attitude towards cauliflower ear

\begin{tabular}{|c|c|c|c|c|c|c|c|c|}
\hline \multirow[b]{2}{*}{$\begin{array}{l}\text { Occasional use of } \\
\text { protective headgear }\end{array}$} & \multicolumn{2}{|c|}{$\begin{array}{c}\text { Male } \\
\text { wrestlers with } \\
\text { cauliflower } \\
\text { ear } \\
(n=28)\end{array}$} & \multicolumn{2}{|c|}{$\begin{array}{c}\text { Male judokas } \\
\text { with } \\
\text { cauliflower } \\
\text { ear } \\
(n=18)\end{array}$} & \multicolumn{2}{|c|}{$\begin{array}{c}\text { Males } \\
\text { without } \\
\text { cauliflower } \\
\text { ear } \\
(n=9)\end{array}$} & \multicolumn{2}{|c|}{$\begin{array}{l}\text { All females } \\
\qquad(n=8)\end{array}$} \\
\hline & $11 \%$ & $3 / 28$ & $50 \%$ & $9 / 18$ & $17 \%$ & $1 / 6$ & $20 \%$ & $1 / 5$ \\
\hline $\begin{array}{l}\text { Treatment for } \\
\text { auricular haematoma }\end{array}$ & $100 \%$ & $28 / 28$ & $89 \%$ & $16 / 18$ & $11 \%$ & $1 / 9$ & $0 \%$ & $0 / 8$ \\
\hline $\begin{array}{l}\text { Treatment by a } \\
\text { doctor }\end{array}$ & $54 \%$ & $15 / 28$ & $61 \%$ & $11 / 18$ & $0 \%$ & $0 / 9$ & $0 \%$ & $0 / 8$ \\
\hline $\begin{array}{l}\text { Would } \\
\text { recommend } \\
\text { treatment }\end{array}$ & $46 \%$ & $13 / 28$ & $56 \%$ & $10 / 18$ & $40 \%$ & $2 / 5$ & $88 \%$ & $7 / 8$ \\
\hline $\begin{array}{l}\text { Would recommend } \\
\text { use of protective } \\
\text { headgear }\end{array}$ & $21 \%$ & $6 / 28$ & $50 \%$ & $9 / 18$ & $20 \%$ & $1 / 5$ & $75 \%$ & $6 / 8$ \\
\hline $\begin{array}{l}\text { Views cauliflower ear } \\
\text { as a desirable } \\
\text { deformity }\end{array}$ & $43 \%$ & $12 / 28$ & $39 \%$ & $7 / 18$ & $20 \%$ & $1 / 5$ & $0 \%$ & $0 / 8$ \\
\hline $\begin{array}{l}\text { Aesthetic } \\
\text { disadvantage }\end{array}$ & $0 \%$ & $0 / 28$ & $0 \%$ & $0 / 18$ & $20 \%$ & $1 / 5$ & $13 \%$ & $1 / 8$ \\
\hline
\end{tabular}

Not all athletes answered each question.

This article is protected by copyright. All rights reserved. 


\section{Table 3 Symptoms}

\begin{tabular}{l|c|ccccc}
\hline \multirow{2}{*}{ Symptom } & \multirow{2}{*}{$\begin{array}{l}\text { Mean } \\
\text { grade }\end{array}$} & 1 & 2 & 3 & 4 & 5 \\
\cline { 3 - 7 } & & \multicolumn{5}{|c}{ Percentage (\%) } \\
\hline Pain & 2.74 & 24 & 13 & 37 & 17 & 9 \\
Warmth & 2.02 & 43 & 28 & 13 & 13 & 2 \\
Dysaesthesia & 1.63 & 63 & 15 & 17 & 4 & 0 \\
Ulcers & 1.59 & 59 & 28 & 9 & 4 & 0 \\
Cold sensitivity & 1.57 & 72 & 7 & 17 & 2 & 2 \\
Earwax problems & 1.50 & 70 & 17 & 7 & 7 & 0 \\
Hearing problems & 1.39 & 70 & 24 & 4 & 2 & 0 \\
Infections & 1.26 & 83 & 11 & 4 & 2 & 0 \\
\hline Sunburn & 1.07 & 96 & 2 & 2 & 0 & 0 \\
\hline
\end{tabular}

Symptoms were graded from 1 to 5 ( $1=$ no harm, $5=$ a lot of harm) $(n=46)$.

Figure 1. Examples of cauliflower ear and the grading of them from 0 to 5 ( $0=$ normal auricle, 5 = extreme cauliflower ear). The image on the left was graded 1 , the middle image reflects grade 3 and the right image was identified as grade 5 .

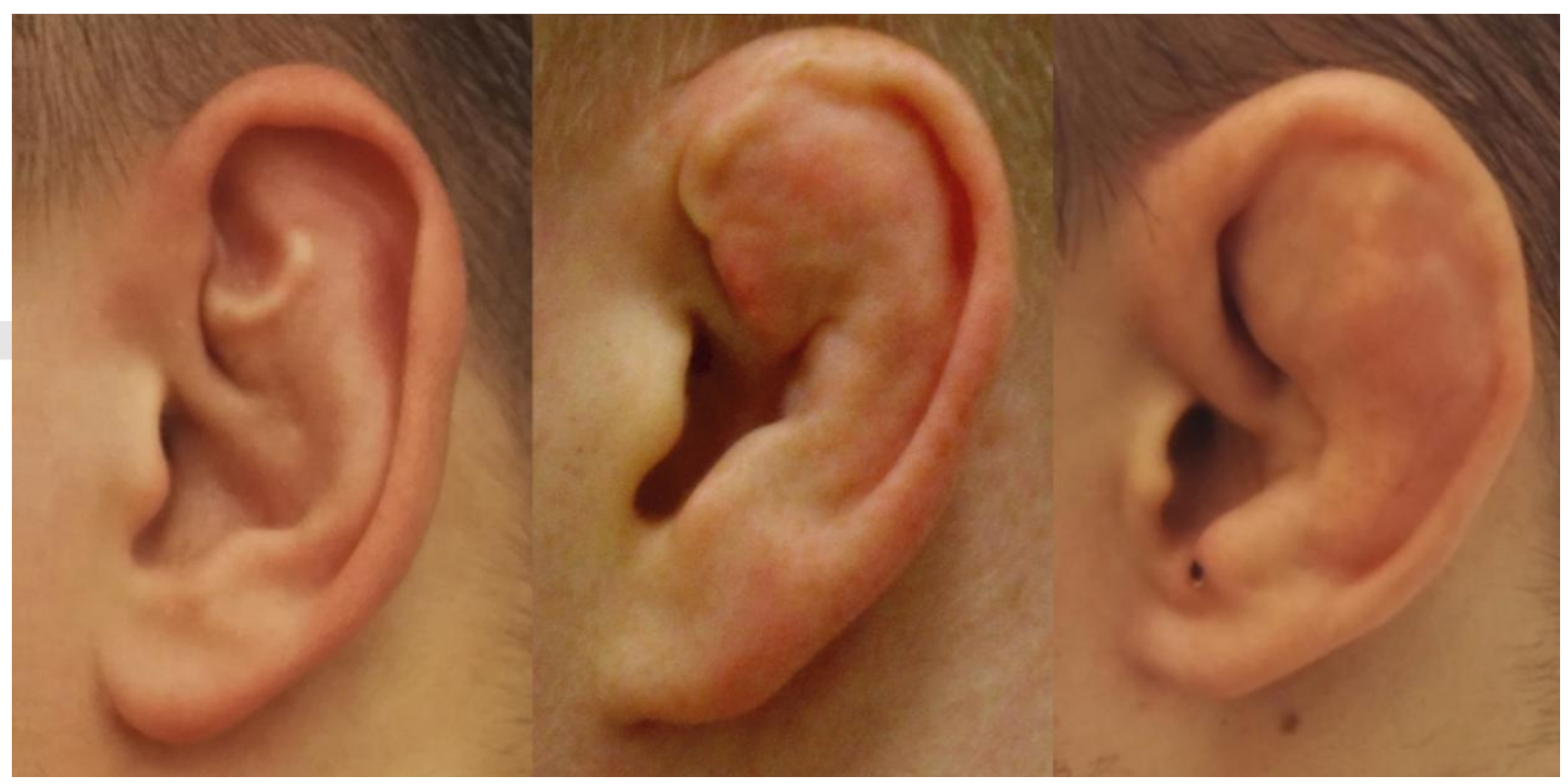

This article is protected by copyright. All rights reserved. 